\title{
Comunicación

\section{Diversidad y desigualdad en las geografías mediáticas: la búsqueda de los sentidos sociales de las prácticas mediáticas}

ANA BERÓNICA PALACIOS GÁMAZ1

Geografias ciudadanas y mediáticas, de la autora María Rebeca Padilla de la Torre, publicado en 2012 por la Universidad Autónoma de Aguascalientes, es ahora la concreción de un proyecto enfocado a inteligir, a apropiarse de una realidad necesaria de analizar, interpretar y comprender cuyo nodo es la ruptura de las certidumbres, de la seguridad, de los cambios en la vida cotidiana que se conforma en referente de identidad. Si bien la autora parte de una perspectiva local y sus problemas urbanos, esto permite la comprensión de las tensiones que se configuran entre lo local y lo global, y la interrelación clave que se da con los sistemas de comunicación masivos y digitales en la conformación de las geografías ciudadanas y mediáticas actuales.

1 Universidad Autónoma de Chiapas, México.

Correo electrónico: avgamaz@hotmail.com 
En este texto, María Rebeca Padilla aporta conocimientos y su experiencia personal en los estudios socioculturales con la construcción de su objeto de estudio desde una perspectiva reflexiva y centra el interés en la indagación de los sentidos que tienen las prácticas mediáticas entre la diversidad cultural de los habitantes de una ciudad, en particular de comunidades urbanas con identidades específicas, partiendo de la premisa de que la migración y los medios de comunicación son elementos clave en la trascendencia de lo local y forman parte de los flujos globales contemporáneos.

El estudio da cuenta de las formas en que las diferencias culturales y las desigualdades en el acceso a los medios han configurado nuevas lógicas tanto en lo urbano y lo local en su relación con lo nacional o global, así como en los sentidos de ser un ciudadano. De tal forma que las diferencias entre identidades y culturas generan distintos perfiles socioculturales, en sus diferentes geografías ciudadanas y mediáticas.

El análisis de los perfiles socioculturales se ancla en algunas comunidades urbanas situadas en la ciudad de Aguascalientes: la de los japoneses (comunidad extranjera), los defeños (inmigrantes nacionales), los mormones (minoría religiosa) y los aguascalentenses nativos. Dichas comunidades conforman escenarios simbólicos con particularidades identitarias, de prácticas mediáticas y maneras de asumir y ejercer la ciudadanía. Es precisamente esta cuestión la que aborda y resuelve la autora: cómo se articulan las prácticas mediáticas en la construcción de identidades urbanas. El estudio de casos permite trasladar la reflexión hacia la ciudadanía contemporánea desde los sentidos de pertenencia, la lógica de las prácticas mediáticas y los problemas urbanos.

La autora asume la ciudadanía formal como el estatus, el sentido de pertenencia, la relación con el territorio, los valores y las prácticas ciudadanas, y la analiza desde la dimensión cultural. Es aquí donde se sitúa un relevante aporte, ya que cuestiona el concepto tradicional de ciudadanía, su homogeneidad y que los cinco elementos que la integran (un estatus de pertenencia en una unidad política, valores hacia el bien común de una unidad política, participación política, conocimiento y comprensión de un corpus de leyes y procesos de gobierno) se comparten en condiciones de igualdad por todos los ciudadanos, sin embargo, estos elementos se desarticulan en la realidad de acuerdo con los distintos perfiles socio- 
culturales de ciudadanía; así mismo, la autora agrega otros elementos relevantes para la comprensión de las dinámicas de la ciudadanía contemporánea como: la relación con el territorio físico de la ciudad, los valores que orientan las prácticas y definen cada identidad, los anhelos y proyectos de ciudad, las prácticas que los ciudadanos llevan a cabo para mejorarla y las relaciones interculturales entre identidades urbanas.

La construcción de ciudadanía se entiende en relación con el Estadonación, en las escalas de ciudadanía mundial, entre ciudades mundiales y en la ciudad. Así mismo, aborda la identidad colectiva para distinguir los perfiles socioculturales de ciudadanía y las prácticas mediáticas las relaciona con la presencia intermedial de los medios, los cambios en la percepción y la experiencia del tiempo y el espacio en los procesos de globalización. Así, desde una metodología sociocultural, interpretativa y cualitativa, analiza lo mediático y urbano a partir de la experiencia y producción de significados del actor social. De esta manera, a través de un complejo, minucioso y valioso trabajo etnográfico, Padilla nos proporciona las coordenadas precisas para comprender estas geografías ciudadanas y mediáticas.

\section{LA CIUDAD DESDIBUJADA}

Aguascalientes se caracterizó como una ciudad pequeña, tradicional, conocida como tierra de gente buena, de economía agrícola, de pequeñas industrias en manos de familias lugareñas, liderazgos del magisterio y una política de cacicazgo del Partido Revolucionario Institucional (PRI); pero en la década de los ochenta esta ciudad se transforma aceleradamente con su apertura a la economía global, la llegada de capital extranjero (japonés), la intensificación de su industrialización, la alternancia del partido político en el poder, el incremento de flujos migratorios, de la desigualdad social, de la delincuencia, el narcotráfico y la complejidad de su diversidad social, cultural y política.

\section{Primer escenario simbólico: la comunidad de japoneses}

La inmigración japonesa en México data de la segunda mitad del siglo XX y actualmente se caracteriza como una población "visitante", de paso, transitoria y sin intención de arraigarse, la cual se rige por la ló- 
gica empresarial transnacional y decide su permanencia en la ciudad de Aguascalientes, como en otras ciudades corporativas a nivel mundial, ya que la empresa es entendida como la colectividad que sostiene y otorga fortaleza a la familia y a su nación. Esta lógica empresarial dicta las pautas de sentido de la vida privada y laboral de los japoneses. La empresa conforma un modo de vida que se centra en el trabajo y lo que representa para la comunidad. El mundo laboral es eminentemente masculino, con una dedicación total a los requerimientos de la empresa, y la educación es orientada en esta lógica; en tanto las mujeres casadas y con hijos, incluso con altos niveles de escolaridad, se dedican exclusivamente al cuidado de la familia, la educación de los hijos y la administración de los bienes familiares. Los valores que orientan las prácticas de los japoneses, el corazón japonés como le denominan, son valores culturales que rigen su conducta, especialmente el respeto al tiempo y el espacio del otro.

Anhelan que la ciudad de Aguascalientes sea cosmopolita, segura, sustentable y con condiciones para el desarrollo de la empresa transnacional. Expresan prejuicios hacia lo latinoamericano y deciden vivir excluidos del resto de los habitantes de la ciudad. Manifiestan un alto compromiso con su comunidad, pero escaso con la ciudad que habitan, ya que procuran mantener una comunidad cerrada y pasar inadvertidos; mantienen una exclusividad en los espacios donde viven, la escuela para los niños y espacios de recreación, donde solo utilizan el idioma japonés.

En cuanto a sus prácticas mediáticas, los medios de comunicación son utilizados para informarse y comunicarse, principalmente sobre Japón, en segundo plano México y en tercer plano lo local, constituyen un elemento fundamental en su vida laboral y cotidiana, y les permiten crear espacios en común entre puntos lejanos de la geografía. Así mismo, las empresas y la embajada japonesa son actores que proporcionan información, particularmente medidas de alerta y preventivas de seguridad para sus ciudadanos, que refuerzan la percepción de un entorno peligroso, el prejuicio y el temor a la alteridad.

\section{Segundo escenario simbólico: la comunidad de defeños}

Esta comunidad está constituida por inmigrantes del Distrito Federal, debido a la descentralización del Instituto Nacional de Estadística y 
Geografía (INEGI) en la década de los ochenta, los trabajadores de esta institución aceptaron su cambio laboral a la ciudad de Aguascalientes, pero tanto las condiciones adversas en que se situaron con el cambio de ciudad (vivienda, servicios e infraestructura), como por las actitudes de discriminación que sufrieron en esta ciudad, generaron una solidaridad y un sentimiento de comunidad como defeños y trabajadores del INEGI. Esta comunidad expresa una situación socioeconómica variable, aún permea una identidad de inmigrantes expuestos a discriminación por prejuicios basados en el lugar de pertenencia y de conductas. Los defeños expresan un sentido de arraigo, de pertenencia ganada, a la ciudad de Aguascalientes. Los valores culturales, que consideran referentes mexicanos, orientan sus prácticas. La institución federal donde trabajan y el fraccionamiento donde viven son organizaciones que definen su identidad. Manifiestan que anhelan una ciudad cosmopolita, segura, sustentable, con mayor oferta de educación pública y empleos, y sin discriminación hacia los inmigrantes. Las relaciones que han establecido se configuran en un proceso difícil de enfrentamiento e integración, han desarrollado un alto compromiso con su propia comunidad y la institución donde laboran, y consideran que han realizado aportaciones a la sociedad aguascalentense, especialmente en el plano cultural.

Respecto de las prácticas mediáticas de los defeños, el cambio de espacio de vida por la migración laboral y de las características del entorno mediático, generó su preferencia como audiencia de los medios nacionales, ya que los medios locales aguascalentenses, privados y públicos, expresan una perspectiva conservadora y severidad contra lo que atente contra el orden tradicional. Es en el campo laboral donde las Tecnologías de la Información y la Comunicación (TIC) tienen una fuerte centralidad.

\section{Tercer escenario simbólico: la comunidad de mormones}

Esta comunidad religiosa transnacional (la Iglesia de Jesucristo de los Santos de los Últimos Días) está conformada por una población híbrida entre locales e inmigrantes nacionales, principalmente defeños, cuya situación socioeconómica es variable. Constituyen una otredad ante la mayoría de la población católica, invisibilizados por ser minoría. Sus prácticas son orientadas por valores religiosos y la Iglesia transnacional 
integra sus identidades. Esta comunidad anhela una ciudad con valores tradicionales, segura, sustentable, con mayor oferta de educación pública y empleo, que valore en condiciones de igualdad su propuesta religiosa. La invisibilidad de esta comunidad religiosa está relacionada con el sistema de medios de la localidad que generalmente emite una imagen negativa de ésta y expresa el poder de la Iglesia católica. Con el apoyo de soportes mediáticos, es una comunidad productora y audiencia que facilita su vida religiosa y estructura una comunidad transnacional; sin embargo, se expresan diferencias en el acceso a los medios con fines religiosos por factores de nivel educativo y económico.

\section{Cuarto escenario simbólico: la comunidad aguascalentense}

Esta comunidad está constituida por dos grupos diferenciados por su nivel socioeconómico: los pobres de la orilla de la ciudad y los ricos de la ciudad, del Club Campestre. El origen de ambos grupos es la ciudad de Aguascalientes. Los primeros, los de la orilla, tienen una situación socioeconómica desfavorable, están marginados y estigmatizados como pobres y delincuentes. Los valores que orientan sus prácticas son tradicionales y de equidad social. La colonia donde habitan y su organización de colonos integran sus identidades. Expresan que anhelan una ciudad segura, que distribuya equitativamente su riqueza y servicios entre sus habitantes, y les garantice justicia. En la ciudad están excluidos de las zonas de privilegios y económicamente son incluidos como obreros por los japoneses. Tienen un alto compromiso con su comunidad y la ciudad. Así mismo, manifiestan una intensa organización vecinal para el logro de la mejora de sus condiciones de vida. En cuanto a sus prácticas mediáticas, es notoria la ausencia de ellas en estos colonos debido a sus condiciones de pobreza, y el acceso a la prensa se centra en información local del lugar donde viven.

En cuanto a los aguascalentenses del Club Campestre, estos son originarios de esta ciudad, tienen una situación económica favorable y constituyen la élite local, su arraigo a la ciudad se legitima en el origen y la élite urbana local. Sus prácticas son orientadas por valores tradicionales y la organización que integra su identidad es el club deportivo y social. Manifiestan que anhelan una ciudad segura, sustentable, con un desarrollo económico donde prevalezcan valores tradicionales y su 
poder como élite. Conforman relaciones de exclusión con las otras comunidades y tienen prejuicios contra los defeños, las clases bajas y los no católicos. Esta comunidad expresa una desigualdad en el acceso a los medios de comunicación debido a las competencias generacionales que se requieren como usuarios de dichas tecnologías.

Después de este breve recorrido por los puntos centrales que caracterizan los perfiles socioculturales de estas comunidades, la autora demuestra en su estudio cómo la ciudadanía constituye un estado de mutación, ya que los elementos que la conforman se articulan y desarticulan de manera dinámica ante la configuración de otros sentidos diferentes a los tradicionalmente ligados a un territorio o Estado-nación, y los lazos vinculantes de los sentidos de pertenencia son la identidad y la percepción de incertidumbre como una constante. La ampliación de la diferenciación social, cultural y económica de las sociedades ha generado una ciudadanía tanto diversa como inequitativa.

Una aportación clave de este estudio tiene que ver con las geografías mediáticas, que expresan las maneras en que las comunidades desarrollan estrategias con relación a los medios, las cuales apropian y conforman relaciones entre lugares para constituir un espacio mediático propio.

Finalmente, considero que un fino valor de este estudio es la capacidad de extrañamiento de la autora, ante lo propio y lo ajeno, y vuelve la mirada reflexiva al espacio de origen, a sus transformaciones, sus contradicciones y sus desigualdades, y expresa en su discurso lo que Octavio Paz (1981) interpreta cuando traduce los haikus del poeta japonés Kobayashi Issa: "El regreso al pueblo natal, como siempre, es una nueva herida". La autora nos expone esas vetas abiertas para seguir indagando sobre los sentidos de estas geografías ciudadanas y mediáticas de comunidades diversas situadas en las tensiones entre lo local y lo global.

\section{Bibliografía}

Basho, M. (1981). Sendas de Oku. [O. Paz \& E. Hayashiya, Traductores]. Barcelona, España: Editorial Seix Barral. 